Renato Duro Dias ${ }^{1}$ Mariana Lannes Lindenmeyer ${ }^{1}$ Fabiane Simioni ${ }^{1}$ Wesley Tomaz ${ }^{1}$

\title{
VIOLÊNCIA OBSTÉTRICA E O PARADIGMA DO DISCURSO HEGEMÔNICO NA ÁREA DA SAÚDE
}

Obstetric violence and the paradigm of hegemonical discourse in the health area

${ }^{1}$ Universidade Federal do Rio Grande. Faculdade de Direito. Programa de Pós-Graduação em Direito. Rio Grande/RS, Brasil.

Correspondência: Mariana Lannes Lindenmeyer.E-mail: mariana_lannes@hotmail.com

Recebido: 23/06/2019. Revisão: 28/12/2019. Aprovado: 27/02/2020. 


\section{RESUMO}

O presente artigo investigou o processo de naturalização das práticas de violência obstétrica e de constante silenciamento sofrido pelas mulheres. $\mathrm{O}$ estudo pretendeu verificar se a hegemonia do discurso dos profissionais de saúde interfere na percepção dos casos de violência obstétrica. A partir da perspectiva histórica sobre o tema, foi possível compreender a origem do debate e sua delimitação enquanto violência sofrida pelas mulheres na assistência ao parto ou ao abortamento. Em um segundo momento, evidenciada a problemática em torno das relações entre profissionais de saúde e pacientes, o estudo tratou da teoria política de Ernesto Laclau e de Chantal Mouffe, matriz teórica de análise dos fenômenos sociais e políticos. No presente caso, esta teoria compôs a análise sobre a formação do discurso hegemônico existente na área da saúde. Demonstrada tal hegemonia discursiva, demonstrou-se ainda a interferência dessa realidade na percepção dos casos de violência obstétrica. Por fim, analisou-se alternativas para a transformação do discurso em hegemonia.

\section{Palavras-Chave}

Violência Obstétrica; Mulheres; Teoria do Discurso; Hegemonia.

\section{ABSTRACT}

This article investigated the process of naturalization of obstetric violence practices and the constant silencing suffered by women. The study intended to verify whether the hegemony of the health professionals discourse interferes in the perception of cases of obstetric violence. From the historical perspective on the subject, it was possible to understand the origin of the debate and its delimitation as violence suffered by women in childbirth or abortion care. In a second moment, when the problems surrounding the relationship between health professionals and patients were highlighted, the study dealt with the political theory of Ernesto Laclau and Chantal Mouffe, a theoretical matrix for the analysis of social and political phenomena. In the present case, this theory comprised the analysis of the formation of the hegemonic discourse existing in the health area. Demonstrated such discursive hegemony, the interference of this reality in the perception of cases of obstetrical violence was also demonstrated. Finally, alternatives for transforming discourse into hegemony were analyzed.

\section{Keywords}

Obstetrical Violence; Women; Discourse Theory; Hegemony. 


\section{Introdução}

Os direitos reprodutivos e sexuais das mulheres são historicamente violados, sobretudo por se tratar justamente do corpo feminino, objetificado em uma sociedade patriarcal. A violência obstétrica - uma entre as diversas formas de violência sofridas pelas mulheres - é compreendida como toda e qualquer violação ocorrida no âmbito da assistência à gravidez, ao pré-parto, ao parto e ao pós-parto, bem como nas hipóteses de atendimento decorrente do abortamento. Todavia, a forma como esse tipo de violência é normalizado pela sociedade evidencia sua peculiar e problemática característica: a banalização, o verdadeiro processo de naturalização por meio do qual esse tipo de violação e desrespeito ao corpo feminino é considerado normal, procedimental nos serviços de saúde.

O estudo do tema invariavelmente acarreta o debate em torno do silenciamento das mulheres em hospitais e maternidades brasileiros, provocando o questionamento acerca do motivo pelo qual, em muitos dos procedimentos, as mulheres sujeitas à situação de violência obstétrica - tanto física quanto psicológica - não são ouvidas pelos profissionais de saúde que lhes estão prestando atendimento. O conhecimento da mulher sobre seu próprio corpo e, principalmente sobre sua dor, é subjugado frente ao conhecimento médico. Assim, a partir da reprodução sistêmica e continuada de determinados discursos é que restou consolidado o paradigma da hegemonia do discurso dos profissionais de saúde, sobretudo médicos, nos ambientes hospitalares. Tal presunção torna-se um problema real e evidente diante das práticas de violência obstétrica, visto que a voz da mulher sobre o fato detém menor condição de romper esta hegemonia, ou seja, tem ínfimas possibilidades de ser minimamente considerada crível.

A partir dessa realidade, utilizando o método dedutivo e a pesquisa bibliográfica, o presente estudo questiona: a hegemonia do discurso dos profissionais de saúde é capaz de interferir na percepção dos casos de violência obstétrica? Para investigar tal problema, optou-se por analisar esse fenômeno social (hegemonia do discurso na área da saúde) a partir de diretrizes estabelecidas pela teoria política do discurso proposta por Ernesto Laclau e Chantal Mouffe.

\section{Violência obstétrica: perspectivas históricas e delimitações sobre o tema}

\section{Perspectivas históricas e a concepção do termo}

Alguns marcos históricos foram fundamentais para a compreensão de que o sofrimento da mulher na assistência à sua saúde caracteriza, na verdade, uma forma de violência, a qual deve ser problematizada e compreendida como tal. 
A Declaração Universal de Direitos Humanos ${ }^{1}$ constituiu um desses marcos. Ainda que aborde o tema dos direitos humanos enquanto categoria geral, o documento histórico revelou-se um incentivo para os movimentos sociais no processo de constituição dos sujeitos envolvidos e de sua vocalização em sociedade ${ }^{2}$. A partir desse novo cenário, os relatos sobre a violência contra as mulheres nas situações de assistência ao parto ou à maternidade passam a se tornar mais visíveis.

No final da década de 1950, o silêncio sobre o tema foi rompido por uma reportagem da revista norte-americana Ladies Home Journal intitulada "Crueldade nas Maternidades”. A publicação relatou práticas, sofridas por parturientes, de sedação profunda - acarretando alucinações -, uso de amarras e algemas nas mãos das pacientes e uso do fórceps, entre outras formas de violência contra aquelas mulheres. O impacto da matéria motivou providências por parte da Sociedade Americana de Psicoprofilaxia em Obstetrícia, que estabeleceu novas diretrizes e cuidados na assistência ao parto ${ }^{3}$.

No mesmo período, em manifestações em igual sentido no Reino Unido, teóricas feministas denunciaram as condições ofertadas pelos hospitais e a brutalidade do tratamento médico nos procedimentos de pré-parto, parto e pós-parto. Entre as décadas de 1960 e 1980, publicações oriundas dos movimentos feministas foram igualmente essenciais para conferir publicidade às práticas violentas sofridas pelas mulheres nas maternidades, bem como contribuíram para o aumento de denúncias. A Conferência Internacional sobre População e Desenvolvimento, realizada em 1994 do Cairo, Egito, foi de significativa relevância para a discussão, pois "o conceito de cidadão foi inserido nas relações com a vida sexual e reprodutiva, incluído [sic] questões de direitos e deveres"4. Assim, a partir desse marco, os direitos sexuais e reprodutivos foram caracterizados enquanto direitos sociais, de promoção obrigatória pelos entes estatais.

No âmbito da América Latina, citam-se dois estudos: um realizado em 1998 no Peru sobre as violências praticadas contra as mulheres nos serviços públicos de saúde; e o pioneiro trabalho brasileiro intitulado "Espelho de

\footnotetext{
${ }^{1}$ UNICEF. Declaração Universal dos Direitos Humanos. Disponível em: https://www.unicef.org/brazil/ declaracao-universal-dos-direitos-humanos. Acesso em: 31 maio 2021.

2PULHEZ, Mariana Marques. “Parem a violência obstétrica: a construção das noções de 'violência' e 'vítima' nas experiências de parto. RBSE- Revista Brasileira de Sociologia da Emoção, v. 12, n. 35, p. 545, ago. 2013. ISSN 1676-8965. Disponível em: https://grem-grei.org/wp-content/uploads/2020/05/n35_ RBSEv12n35ago2013.pdf.

${ }^{3}$ DINIZ, Simone Grilo et al. Violência obstétrica como questão para a saúde pública no Brasil: origens, definições, tipologia, impactos sobre a saúde materna e propostas para a sua prevenção. Journal of Human Growth and Development, v. 15, n. 3, p 377-384, 2019. Disponível em: http://pepsic.bvsalud.org/pdf/ rbcdh/v25n3/pt_19.pdf. http://dx.doi.org/10.7322/jhgd.106080. p. 2.

${ }^{4}$ MARIANI, Adriana Cristina; NASCIMENTO NETO, José Osório do. Violência obstétrica como violência de gênero e violência institucionalizada: breves considerações a partir dos direitos humanos e do respeito às mulheres. Cad. Esc. Rel. Int. (UNIBRASIL), v. 2, n. 25, p 56, jul./dez. 2016. Disponível em: https:// portaldeperiodicos.unibrasil.com.br/index.php/cadernosdireito/article/view/3060/2630.
} 
Vênus", de 1981, que descreveu a violência sofrida no parto institucionalizado (hospitalar) ${ }^{5}$. Temos ainda a pesquisa "Mulheres brasileiras e gênero nos espaços público e privado", na qual concluiu-se que uma em cada quatro mulheres sofreram algum tipo de experiência violenta no parto ${ }^{6}$. Essas experiências, pesquisas e publicações exemplificam meios de denúncia das práticas discriminatórias e violentas na assistência à saúde e, sobretudo, na assistência ao parto, dando visibilidade ao tema.

A partir dessa visibilidade conferida pelos movimentos de humanização do parto é que foi possível construir uma agenda específica e aprofundar o tema, tanto em sua concepção quanto nos mais diversos recortes. A expressão "violência obstétrica" é empregada para tratar de diversos tipos de violência contra a mulher. O primeiro país a tipificar a violência obstétrica foi a Venezuela:

Entende-se por violência obstétrica a apropriação do corpo e dos processos reprodutivos das mulheres por profissional de saúde que se expresse por meio de relações desumanizadoras, de abuso de medicalização e de patologização dos processos naturais, resultando em perda de autonomia e capacidade de decidir livremente sobre seu corpo e sexualidade, impactando negativamente na qualidade de vida das mulheres ${ }^{7}$.

Nesse sentido, qualquer intervenção "indevida, não autorizada ou sequer informada, até mesmo abusiva, sobre o corpo ou processo reprodutivo da mulher"s constitui violência obstétrica e afronta a dignidade, a autonomia e a liberdade da parturiente. Essa violação ocorre tanto fisicamente quanto psicologicamente. Assim, constitui violência obstétrica qualquer forma de violência ocorrida no período de assistência à gravidez, incluindo pré-parto, parto, pós-parto e abortamento9.

A violência obstétrica pode ser dividida em formas de abuso e desrespeito, categorizadas de acordo com o tipo de abuso e o respectivo direito infringido. São as seguintes categorias de desrespeito e abuso:

a) abuso físico; b) imposição de intervenções não consentidas; intervenções aceitas com base em informações parciais ou distorcidas; c) cuidado não confidencial ou não privativo; d) cuidado indigno e abuso verbal; e) discriminação baseada em certos atributos; f) abandono, negligência ou recusa de assistência; e g) detenção nos serviços ${ }^{10}$.

\footnotetext{
${ }^{5}$ DINIZ, Simone Grilo et al. op. cit., p. 2.

${ }^{6} / d$. loc., cit.

${ }^{7}$ DINIZ, Simone Grilo et al. op. cit., p. 3.

${ }^{8}$ MARIANI, Adriana Cristina; NASCIMENTO NETO, José Osório do. op. cit., p. 51.

${ }^{9}$ DINIZ, Simone Grilo et al. op. cit., p. 3.

${ }^{10}$ Id. loc., cit.
} 
Exemplo de violência obstétrica enquadrada nesta categorização é a imposição de intervenções não consentidas, o que viola o direito à informação, ao consentimento informado e à recusa e o direito de escolha. Isso ocorre costumeiramente na realização do procedimento de episiotomia, no desrespeito ao plano de parto, na falta de esclarecimento dos danos da cesariana, entre outros.

Estabelecida a concepção do termo "violência obstétrica" a partir de sua construção histórica, passa-se a investigar a situação brasileira nesta problemática seara.

\section{Delimitações da violência obstétrica no Brasil}

A violência obstétrica envolve procedimentos e métodos muito naturalizados nos serviços de saúde, por isso o Brasil carece de mais e melhores indicadores sobre essa prática nos hospitais, maternidades e atendimentos médicos existentes no país. Ainda assim, pesquisadoras e pesquisadores que debruçam esforços para investigar e analisar o tema concluíram estudos com dados alarmantes sobre a situação brasileira.

Em 2009, por exemplo, uma pesquisa desenvolvida pelo Instituto Brasileiro de Geografia e Estatística (IBGE) concluiu que 98\% dos partos no Brasil são realizados em hospitais, sendo que em torno de $50 \%$ são realizados via cirúrgica, por cesárea ${ }^{11}$. Já naquela época, o país liderava o ranking mundial de cesáreas, com taxa muito superior aos 15\% indicados pela Organização Mundial de Saúde (OMS). A pesquisa "Nascer no Brasil: inquérito nacional sobre parto e nascimento (2011 a 2012)"12, realizada em 2011 e 2012 com coordenação da Escola Nacional de Saúde Pública Sergio Arouca da Fundação Oswaldo Cruz (ENSP/Fiocruz), concluiu que, desde 1970, o índice de procedimentos de cesárea vinha aumentando de forma vertiginosa, alcançando $52 \%$ dos partos no país. No setor privado, o índice de cesáreas relatado foi de $88 \%$ dos procedimentos, enquanto no setor público o índice foi de $46 \%$.

Ainda em 2012, foi instaurada a Comissão Parlamentar Mista de Inquérito no Congresso Nacional com o fim de investigar a violência contra as mulheres no Brasil e a atuação do poder público, sendo que um dos temas debatidos foi justamente a violência no parto. $\mathrm{Na}$ oportunidade, foram expostos os dados colhidos pela organização não-governamental "Parto do Princípio", no dossiê "Parirás com Dor" ${ }^{\prime \prime}$, o qual ressalta os dados alarmantes de cesarianas realizadas no país e o

\footnotetext{
${ }^{11}$ PULHEZ, Mariana Marques. op. cit., p. 527.

${ }^{12}$ LEAL, M. C.; GAMA, S. G. N. Nascer no Brasil: Sumário Executivo Temático da Pesquisa. In: ESCOLA NACIONAL SÉRGIO AROUCA - FUNDAÇÃO OSWALDO CRUZ. Nascer no Brasil: inquérito nacional sobre parto e nascimento (2011 a 2012). Disponivel em https://nascernobrasil.ensp.fiocruz.br/wp-content/ uploads/2019/12/sumario_executivo_nascer_no_brasil.pdf. Acesso em: 04 jun. 2021

${ }^{13}$ OBSTÉTRICA “Parirás com dor". Dossiê elaborado pela Rede Parto do Princípio para a CPMI da Violência Contra as Mulheres. Brasília-DF: Senado Federal, 2012. p. 81. Disponível em: https://www.senado.gov.br/ comissoes/documentos/SSCEPI/DOC\%20VCM\%20367.pdf. Acesso em: 19 jun. 2019.
} 
descumprimento da Lei do Acompanhante (Lei n. 11.108/2005) ${ }^{14}$, bem como elenca as principais violências relatadas pelas entrevistadas, entre as quais: a episiotomia rotineira e desnecessária, cuja ocorrência foi estimada pelo estudo em $94 \%$ dos partos normais no Brasil; intervenções com o intuito de acelerar o parto, a exemplo da denominada manobra de Kristeller; a ausência de informações à parturiente sobre os procedimentos realizados; a não aplicação de analgésicos quando necessário ou em determinados grupos de mulheres; a pressão pela realização de procedimentos em desacordo com o planejado, a exemplo das cesarianas; a inexistência de plano de parto; a violência de ordem verbal, psíquica e moral; entre outros tipos de violação.

O citado aumento no número de cesáreas - procedimento cirúrgico de risco -, aliado a outros procedimentos violentos - a exemplo do manejo agressivo no parto vaginal, do impedimento da presença do acompanhante e da negligência no atendimento, principalmente nas hipóteses de abortamento, entre outros -, influencia diretamente na mortalidade: estima-se que $23 \%$ das mortes maternas no Brasil sejam decorrentes do aumento dessas taxas ${ }^{15}$. Estes são alguns dos dados que evidenciam a recorrente ocorrência de violência obstétrica no Brasil e a gravidade do tema.

Diante deste cenário, importante verificar de que forma o ordenamento jurídico está enfrentando o tema. Como já citado anteriormente, o reconhecimento dos direitos reprodutivos e sexuais como direitos humanos foi de fundamental importância para o enfrentamento da violência obstétrica, especialmente em dois documentos internacionais:

Duas ações importantes para a consolidação desses direitos como direitos humanos foram o Plano de Ação da Conferência Internacional sobre População e Desenvolvimento, desenvolvido no Cairo em 1994, e o documento resultante da IV Conferência Mundial da Mulher, realizada em Pequim em 1995 (FUNDO DE POPULAÇÃO DAS NAÇÕES UNIDAS, 2004, p.21-22). Essas duas ações reconheceram a reprodução e a sexualidade humana como bens jurídicos merecedores de proteção específica ${ }^{16}$.

Por sua vez, a Conferência Internacional Sobre Tecnologias Apropriadas ao Parto, realizada em 1985 pela OMS, pela Organização Pan-Americana da Saúde (OPAS) e pelo departamento regional da OMS nas Américas teve como foco a

\footnotetext{
${ }^{14}$ BRASIL. Lei 11.108, de 07 de abril de 2005. Altera a Lei n. 8.080, de 19 de setembro de 1990, para garantir às parturientes o direito à presença de acompanhante durante o trabalho de parto, parto e pósparto imediato, no âmbito do Sistema Único de Saúde - SUS. Disponível em: http://www.planalto.gov.br/ ccivil_03/_Ato2004-2006/2005/Lei/L11108.htm - Acesso em: 22 jun. 2019.

${ }^{15}$ DINIZ, Simone Grilo et al. op. cit., p. 4.

${ }^{16}$ PEÑA, Rafaela de Miranda Ochoa. Vidas cortadas: a violência obstétrica sob uma perspectiva de gênero. 2016. Monografia (Graduação em Direito) - Faculdade de Direito, Universidade de Brasília, Brasília-DF, 2016. p. 29. Disponível em: https://bdm.unb.br/bitstream/10483/14788/1/2016_ RafaelaDeMirandaOchoaPena_tcc.pdf.
} 
assistência ao parto e concluiu pelas seguintes recomendações: o direito de informação sobre o parto, o direito ao bem-estar e à presença de acompanhante, o direito ao contato com o bebê, o direito a não sofrer pressão pelo parto cirúrgico, entre outros.

No Brasil, exceto pela Lei do Acompanhante, inexiste proteção legal específica sobre o parto humanizado, estando a proteção limitada a portarias do Ministério da Saúde, tais como a Portaria n. 1.067/2005 ${ }^{17}$ (princípios e diretrizes do atendimento à saúde da mulher), a Portaria n. 1.820/2009 (direitos e deveres dos usuários dos serviços de saúde) e a Portaria n. $1.459 / 2011^{19}$, que trata da Rede Cegonha no âmbito do Sistema Único de Saúde (SUS) como política para garantir os direitos reprodutivos, especialmente o planejamento da gravidez, e o direito a tratamento e procedimentos humanizados no parto e à criança. Esta última portaria é de grande relevância enquanto normativa de política pública de assistência ao parto. Todavia, praticamente nada é conhecido sobre sua aplicação no sistema de saúde brasileiro.

Nesse sentido, resta evidente a carência de uma normativa específica sobre o tema da violência obstétrica no Brasil, sendo que a política de combate a ela baseia-se em orientações internacionais e normativas regulamentadoras sem força de lei. Ora, a ausência de proteção legal demonstra que o tema é tratado de forma secundária no Brasil, carecendo não só de melhores políticas públicas, mas também de adequada proteção jurídica.

\section{Teoria do discurso: análise das articulações discursivas e do poder hegemônico}

As premissas e delimitações sobre a violência obstétrica são fundamentais para a compreensão do tema. Entretanto, a discussão em torno do discurso hegemônico dos profissionais de saúde precede, por exemplo, o aprofundamento do debate quanto à proteção normativa dos direitos das mulheres vítimas de violência obstétrica.

Certamente qualquer evolução neste sentido deverá abarcar o problema existente em torno das relações estabelecidas no atendimento junto aos serviços de saúde, sobretudo pela desigualdade existente entre a voz da mulher e a dos profissionais de saúde envolvidos. Em suma, o ambiente hospitalar, além de pouco acolhedor, revela-se como cenário propício para as disputas discursivas em torno da hegemonia. Situações de violação como as narradas anteriormente são diariamente

\footnotetext{
${ }^{17}$ MINISTÉRIO DA SAÚDE - MS. Portaria MS $n^{\circ} 1.067$ de 04/07/2005. Institui a Política Nacional de Atenção Obstétrica e Neonatal, e dá outra providências. Disponível em: https://www.legisweb.com.br/ legislacao/?id=193664. Acesso em: 12 maio 2021.

${ }^{18}$ CONSELHO NACIONAL DE SAÚDE. Portaria $n .1 .820$, de 13 de agosto de 2009. Dispõe sobre os direitos e deveres dos usuários da saúde. Disponível em: https://conselho.saude.gov.br/ultimas_noticias/2009/01_ set_carta.pdf. Acesso em: 12 maio 2021.

${ }^{19}$ MINISTÉRIO DA SAÚDE. Portaria n. 1.459, de 24 de junho de 2011. Institui, no âmbito do Sistema Único de Saúde - SUS - a Rede Cegonha. DIsponível em: https://bvsms.saude.gov.br/bvs/saudelegis/gm/2011/ prt1459_24_06_2011.html. Acesso em: 12 maio 2021.
} 
denunciadas pelas mulheres em atendimento em maternidades e hospitais brasileiros, porém, em grande parte dos casos, são relativizadas e esquecidas.

Vê-se, portanto, a importância de um estudo transdisciplinar sobre o tema, a fim de compreender não só as situações de violência obstétrica, mas também de analisar as relações discursivas e de poder entre os agentes envolvidos nessas hipóteses de violação e o impacto dessas relações hegemônicas na percepção do problema em si. Nesse sentido, a reflexão de Edgar Morin é relevante, pois enfatiza o papel dos estudos transdisciplinares na produção do conhecimento ao longo da história, defendendo a "ecologia" das disciplinas, ou seja, a relação dos conhecimentos agregados em cada área na análise de determinado fenômeno e para produção do conhecimento ${ }^{20}$. Assim, no intuito de analisar as relações de poder existentes no âmbito dos serviços de saúde prestados às mulheres parturientes, a investigação tomará como parâmetro os ensinamentos de Ernesto Laclau e Chantal Mouffe e sua teoria política do discurso.

\section{A teoria do discurso de Ernesto Laclau e Chantal Mouffe}

A teoria política proposta por Ernesto Laclau e Chantal Mouffe teve como marco inicial a publicação de sua obra "Hegemonia e estratégia socialista"21, em 1985. O objetivo dos teóricos políticos foi revisitar os conceitos mais importantes do marxismo, sobretudo a delimitação da hegemonia a partir de aspectos socioeconômicos e de classe, frente ao novo cenário político e social e de indivíduos multifacetados ${ }^{22}$. Denominados de pós-marxistas, os autores apresentaram sua teoria do discurso como uma proposta de constituir novo parâmetro epistemológico de análise dos processos políticos e sociais e do poder hegemônico.

A noção de hegemonia foi criada a partir da tradição marxista, com o fim de pensar as configurações sociais de uma maneira que melhor se coadune com a realidade material observada. Gramsci ${ }^{23}$ apropria-se do conceito de hegemonia previamente traçado por Lênin, expandindo-o para além da "ditadura do proletariado" - destacando o caráter coercitivo - proposta pelo teórico russo; Gramsci destacou a importância de formar uma classe dirigente cuja manutenção no poder se dê pelo consentimento das massas, e não apenas pela força coercitiva. O teórico italiano admitia ser comum um dado grupo social, em situação de subordinação a outro grupo, adotar a concepção de mundo deste, mesmo que esteja em contradição com sua atividade prática; a adoção dessa concepção de mundo imposta mecanicamente

\footnotetext{
${ }^{20}$ MORIN, Edgar. A cabeça bem-feita: repensar a reforma, reformar o pensamento. Tradução de Eloá Jacobina. 10. ed. Rio de Janeiro: Bertrand Brasil, 2004. p. 115.

${ }^{21}$ LACLAU, Ernesto. Mouffe Chantal. Hegemonia e estratégia socialista: por uma política democrática radical. Tradução de Joanildo A. Burity, Josias de Paula Jr. e Aécio Amaral. São Paulo: Intermeios; Brasília-DF: CNPq, 2015.

${ }^{22}$ MENDONÇA, Dianiel de; RODRIGUES, Léo Peixoto. (Orgs.). Pós-estruturalismo e teoria do discurso: em torno de Ernesto Laclau. Porto Alegre: EDIPUCRS, 2008. p. 64.

${ }^{23}$ GRAMSCI, Antônio. Maquiavel, a política e o Estado Moderno. Rio de Janeiro: Civilização Brasileira, 1978. p. 55.
} 
é desprovida de consciência crítica, que somente pode ser obtida a partir de uma disputa de hegemonias contrastantes. O processo de dominação pela hegemonia definido por Gramsci relaciona-se com o conceito de ideologia, inicialmente proposto por Gramsci, mas definido por Laclau e Mouffe como "um todo orgânico e relacional, encarnado em aparatos e instituições, que solda em torno a certos princípios articulatórios básicos a unidade de um bloco histórico"24 ${ }^{\text {. }}$

De qualquer forma, o elemento central da teoria do discurso é a premissa de que o poder hegemônico é produto das articulações discursivas e das divisões sociais, sendo construído a partir do que os autores denominam como processos de antagonismos, evidenciando, assim, a dialética marxista, em que as tensões entre a tese e a antítese produzem uma nova síntese. Assim, entendem que os processos políticos e sociais fáticos, ou seja, os fenômenos visíveis, são resultantes das relações de poder $^{25}$. O discurso é entendido como marco teórico, e não como mera linguagem. A definição conferida pelos autores é de que o discurso representa "a totalidade estruturada", sendo resultado dessas articulações do social, as quais podem constituir ou modificar elementos e, portanto, resultar na constituição de uma identidade coletiva ${ }^{26}$.

O antagonismo, categoria central da teoria, é analisado enquanto elemento intrínseco do ser humano em seu aspecto político e social, a partir da compreensão de que essa categoria é fundamental para a democracia - articulações discursivas antagônicas constituem os processos democráticos e o poder hegemônico - e da concepção de que impossível e inadequada a ideia de consenso, sendo o dissenso (a disputa discursiva) a própria legitimidade de uma democrática sociedade. Dois elementos são importantes na constituição das articulações discursivas e da hegemonia nos âmbitos político e social, bem elucidados por Daniel Mendonça:

Assim, a constituição discursiva de qualquer identidade política ocorre a partir da tensão entre as lógicas da diferença e da equivalência. Do ponto de vista da lógica da diferença, esta se dá pela percepção identitária como tal, o que Laclau (2005) denominou em seu último trabalho, de demandas democráticas, que nascem isoladas num primeiro momento e que por estarem isoladas, estão imersas numa lógica da diferença, pois que não estão articuladas com outras demandas democráticas.

Já, do ponto de vista da lógica da equivalência, Laclau (2005) afirma que esta última somente é possível se as demandas democráticas isoladas passarem a constituir, a partir de um ponto nodal, uma relação de equivalência, ou seja, a articulação dessas

\footnotetext{
${ }^{24}$ LACLAU, Ernesto; Mouffe Chantal. op. cit., p. 132.

${ }^{25}$ Id. Ibid., p. 20.

${ }^{26} / d$. Ibid., p. 178.
} 
diferenças em torno de um ponto discursivo privilegiado que faria sentido a todas elas, possibilitando aí que as mesmas se articulassem em torno de uma lógica equivalencial ${ }^{27}$.

A lógica da diferença ocorre quando determinado discurso é capaz de formar uma identidade social, todavia ainda isolada frente a outros grupos, enquanto a lógica da equivalência ocorre quando é possível identificar um discurso específico capaz de aglutinar diferentes discursos, diferentes perspectivas. O dito discurso específico é denominado pelos autores como ponto nodal. O ponto nodal refere-se a determinado aspecto das relações discursivas, identificado como convergente a ponto de fazer sentido a diferentes discursos e grupos sociais, de maneira a possibilitar uma articulação equivalente. Daí decorre, por exemplo, a hegemonia de determinado discurso.

Assim, as transformações de determinadas concepções sociais advêm justamente dessas articulações discursivas, que passam a produzir sentido quando inseridas no jogo democrático social e representadas por determinadas identidades em sociedade.

Essas são as premissas básicas da teoria do discurso proposta por Ernesto Laclau e Chantal Mouffe que servirão de elementos para a análise dos principais fatores envolvidos nas articulações discursivas no âmbito das práticas de saúde e do discurso hegemônico do profissional da área frente às mulheres parturientes.

\section{A articulação discursiva em torno das práticas de saúde}

As relações de poder estabelecidas no âmbito dos serviços de saúde e a maneira como essas relações influenciam o atendimento das mulheres parturientes, sobretudo como essa influência pode macular a percepção das hipóteses de violência obstétrica, constituem o fenômeno social ora investigado.

É a partir desta compreensão do problema que a teoria do discurso de Mouffe e Laclau constitui alternativa de investigação. Interessante a adoção desta teoria, pois a violência obstétrica atinge todas as mulheres, tanto aquelas atendidas no sistema público quanto as atendidas no sistema privado. Evidente que há recorte de classe e raça nessas práticas, a exemplo da compreensão equivocada de que mulheres negras teriam maior capacidade de suportar a dor ${ }^{28}$. Todavia, os dados obtidos nas pesquisas nacionais evidenciam que a violência obstétrica, por ser naturalizada, é praticada contra as mulheres de forma geral. Exemplo disso é a ocorrência do procedimento de episiotomia, o qual, como referido anteriormente, é praticado em cerca de $94 \%$ dos partos realizados no país.

\footnotetext{
${ }^{27}$ MENDONÇA, Dianiel de; RODRIGUES, Léo Peixoto. (Orgs.). op. cit., p. 64-65.

${ }^{28} \mathrm{LEAL}$, Maria do Carmo et al. A cor da dor: iniquidades raciais na atenção pré-natal e ao parto no Brasil. Cad. Saúde Pública, Rio de Janeiro, v. 33, supl. 1, p. 10, 2017. Disponível em: https://www.scielo.br/pdf/csp/ v33s1/1678-4464-csp-33-s1-e00078816.pdf. http://dx.doi.org/10.1590/0102-311X00078816.
} 
Assim, a concepção da teoria política do discurso de Ernesto Laclau e Chantal Mouffe de que as disputas hegemônicas e de poder no social são conferidas a partir das relações discursivas é plenamente aplicável ao fenômeno do discurso hegemônico no âmbito dos serviços de saúde. A partir dos conceitos da teoria do discurso abordada, é possível estabelecer os principais fatores que constituíram a hegemonia discursiva dos médicos.

A hegemonia do discurso médico tem como primeira característica sua produção histórica, constante e sem contestação, ou seja, sem a adequada articulação discursiva antagônica. $\mathrm{O}$ conhecimento médico é historicamente sobrevalorizado em detrimento de outras formas e áreas do conhecimento, como um todo. Tal fato, por si só, gera a presunção de que o que é dito e defendido pelo profissional da saúde constituirá sempre a mais adequada e melhor decisão ou orientação. Ainda, parte dos procedimentos médicos realizados e contestados como violência obstétrica integra o protocolo dos serviços de assistência médica e obstétrica no país, isto é, os profissionais de saúde são orientados a realizar tais procedimento pelas próprias instituições, inclusive públicas. Ou seja, o discurso dos profissionais de saúde é amparado pelo Estado.

Outro fator do discurso hegemônico dos profissionais de saúde reside justamente no ambiente em que são realizados os procedimentos de assistência às parturientes no pré-parto, parto ou pós-parto. As maternidades e os hospitais, em geral, são ambientes em que o poder discursivo dos profissionais da saúde se sobressai ao que for manifestado pelos pacientes, ainda mais se for referente a qualquer conflito sobre procedimentos ou decisões realizadas durante um procedimento, como é o parto. Há evidentemente uma fragilidade da mulher parturiente perante o profissional da saúde. Por fim, no que tange ao discurso produzido pelos profissionais da saúde, outro aspecto essencial reside na dificuldade que as próprias categorias desses profissionais têm de reconhecer as situações de violência obstétrica quando elas ocorrem. Há grande resistência das categorias de reconhecer minimamente a possibilidade desses eventos de violação ${ }^{29}$.

Por outro lado, o fato de o debate em torno da violência obstétrica ser relativamente recente no Brasil também constitui um fator de desequilíbrio nas articulações discursivas sobre o tema. A preocupação com a violência obstétrica, enquanto violação dos direitos sexuais, reprodutivos e humanos da mulher, é recente e assumida majoritariamente por organizações não governamentais e movimentos sociais. A partir da teoria do discurso, é possível dizer que é bem marcante a presença identitária da lógica da diferença nesse discurso antagônico, ou seja, trata-se

${ }^{29}$ PALHARINI, Luciana Aparecida. Autonomia para quem? O discurso médico hegemônico sobre a violência obstétrica no Brasil. Dossiê Gênero e Ciências: histórias e políticas no contexto Ibero-americano. Cadernos pagu, n. 49, p. 9, 2017, ISSN 1809-4449. Disponível em: https://www.scielo.br/pdf/cpa/n49/1809-4449cpa-18094449201700490007.pdf. http://dx.doi.org/10.1590/18094449201700490007. 
de uma demanda advinda de determinado grupo social ainda isolado no campo político e social. A definição, pela teoria de Laclau e Mouffe, enquanto lógica da diferença se dá justamente pelo isolamento que ainda ocorre quanto ao tema da violência obstétrica - por exemplo, não há incorporação da pauta por parte de outros movimentos sociais.

A evolução dessa identidade calcada na lógica da diferença depende do desenvolvimento de uma lógica da equivalência, sendo esta a articulação de um elemento específico do discurso com outros discursos, produzindo uma identidade em comum. No tema em debate, identifica-se a lógica da diferença e da equivalência a partir do movimento de mulheres, cujo tema identitário é a violência obstétrico. Ainda assim, compreende-se que há um desequilíbrio entre as identidades constituídas pelos movimentos antagônicos referidos, principalmente a partir da concepção histórica de que o discurso dos profissionais da saúde é incontestado, em qualquer medida.

Assim, resta evidenciado o antagonismo entre o discurso majoritário dos profissionais da saúde - com a naturalização de práticas e procedimentos da assistência à saúde, que eles defendem ser necessários para a boa prática obstétrica - e o discurso dos movimentos e organizações de defesa do denominado parto humanizado - em contrariedade àqueles procedimentos e práticas naturalizados, classificados como violência obstétrica. A diferença de força com que cada um desses discursos é produzido na articulação discursiva, a partir dos elementos suprarreferidos, evidencia a dificuldade para a superação e a transformação do paradigma do discurso hegemônico na área da saúde.

\section{O paradigma do discurso na área da saúde: prevalência dos princípios bioéticos na desconstrução do discurso hegemônico}

Evidenciada a forma como são produzidos os discursos hegemônicos na área da saúde, bem como os fatores que acarretam a hegemonia dos discursos e da identidade discursiva dos profissionais de saúde frente ao tema, cabe analisar as consequências dessa realidade nas ocorrências de violência obstétrica.

\section{Os reflexos do discurso hegemônico sobre a violência obstétrica}

A hegemonia do discurso biomédico no âmbito dos serviços de assistência à saúde influencia diretamente a percepção das situações de violência obstétrica.

O primeiro motivo é a naturalização de situações de violência. Parte dos procedimentos contestados de forma veemente por movimentos sociais e organizações, que os consideram como violações, continua a integrar os protocolos de maternidades por todo o Brasil. Assim, e apesar dos dados estatísticos e das pesquisas que demonstram a superação desses procedimentos, muitos deles - a exemplo 
da episiotomia e da manobra de Kristeller - são realizados diariamente e não são percebidos enquanto provocadores de dor e de violação dos corpos femininos.

Em um segundo aspecto, o discurso hegemônico muitas vezes corrobora para que perdurem outros tipos de violência obstétrica. Além dos procedimentos intervencionistas no âmbito físico - os quais são realizados, muitas vezes, sem que a parturiente seja informada e dê seu consentimento -, causam especial espanto as violações de ordem verbal, moral e psíquica sofridas pelas mulheres. Pesquisa realizada em 2010 pela Fundação Perseu Abramo demonstrou o desrespeito sofrido pelas mulheres durante o parto, praticado pelos profissionais responsáveis pela assistência em resposta ao quadro de dor. A frase mais ouvida pelas mulheres, em $15 \%$ dos casos, foi: "Não chora, não, que ano que vem você está aqui de novo". A segunda - "Na hora de fazer não gritou" - foi relatada em $14 \%$ dos casos. De forma geral, $23 \%$ das entrevistadas afirmaram ter sofrido alguma espécie de desrespeito de ordem moral durante o procedimento do parto, sobretudo no parto natural. A pesquisa entrevistou mais de 2 mil mulheres, em 176 municípios do país ${ }^{30}$.

Trata-se, portanto, do menosprezo à dor e à condição relatada pela mulher sob os cuidados de assistência médica, em verdadeira invisibilidade da violência cometida. A hegemonia do discurso biomédico facilita o silenciamento dessas práticas. Ora, as meras situações exemplificativas citadas demonstram não só o desrespeito aos direitos sexuais, reprodutivos e humanos, mas também aos princípios basilares da bioética. O princípio do consentimento deve nortear as relações entre profissionais da saúde e pacientes, sendo compreendido como o dever ético de observar a vontade do paciente frente ao tratamento ou procedimento proposto. Engelhardt relata que este princípio é basilar para a sociedade que se defina plural e deve servir de parâmetro para solucionar questões morais, sendo fundamental para o respeito mútuo ${ }^{31}$.

Por conseguinte, há afronta ao próprio princípio da autonomia, que é justamente a necessidade de observar a capacidade do paciente de produzir escolhas acerca de sua saúde e de seu corpo. Cabe citar a necessidade de que o princípio da autonomia seja garantido e exercido de forma adequada, por meio do fornecimento adequado de informações às mulheres sobre os procedimentos e sobre todos os aspectos relativos à assistência à sua saúde.

Ora, os princípios do consentimento e da autonomia são recorrentemente afrontados nas práticas de violência obstétrica descritas neste estudo. Além da inobservância da autonomia da mulher parturiente, a violência obstétrica acarreta

\footnotetext{
${ }^{30}$ VENTURI, Gustavo; BOKANY, Vilma. Pesquisa de Opinião Pública. Mulheres brasileiras e gênero nos espaços público e privado. Núcleo de Opinião Pública da Fundação Perseu Abramo, ago. 2010. Disponível em: https://apublica.org/wp-content/uploads/2013/03/www.fpa_.org_.br_sites_default_files_ pesquisaintegra.pdf. Acesso em: 19 jun. 2019.

${ }^{31}$ ENGELHARDT JR., H. Tristam. Fundamentos da bioética. São Paulo: Loyola, 1998. p. 140.
} 
igualmente a afronta ao direito de informação, de privacidade, de respeito à dignidade e de igualdade ${ }^{32}$. Evidente que a relação hegemônica estabelecida e o desequilíbrio da articulação discursiva existentes no âmbito da assistência à saúde são fatores que favorecem a ocorrência das situações de violência obstétrica, contribuindo, ainda, para que tais hipóteses permaneçam invisibilizadas enquanto violações dos direitos sexuais, reprodutivos e humanos das mulheres.

\section{Mecanismos de transformação do discurso hegemônico na área da saúde}

Evidenciado o discurso hegemônico biomédico estabelecido nas relações de saúde e seu impacto significativo na percepção e no modo como são apreciadas e debatidas as situações de violência obstétrica, cabe apontar algumas perspectivas apresentadas como elementos de transformação dessa realidade, em prol de um contrabalanceamento dessas relações discursivas entre os profissionais da saúde e as mulheres parturientes.

Primeiramente, a realidade posta evidencia a necessidade de investimento na formação transdisciplinar dos profissionais da saúde, investindo em determinados aspectos do conhecimento humano, para além do conhecimento técnico especializado. Obviamente, o conhecimento especializado e técnico é fundamental e deve ser respeitado. Entretanto, a hiperespecialização acarreta problemática bem narrada por Edgar Morin: ao passo que a especialização do conhecimento gera progressos científicos, o conhecimento fragmentado pode gerar um conhecimento mutilado e, por via de consequência, ocasionará uma prática profissional duvidosa. O desenvolvimento do conhecimento científico foi responsável por extraordinárias descobertas da humanidade, mas, ao mesmo tempo em que há progresso, cada conclusão científica gera incertezas e novos questionamentos, de caráter tanto científico como filosófico ${ }^{33}$. Nesse sentido, a compreensão do filósofo de que o conhecimento é infinito e de que, a cada novo conhecimento, o ser humano se descobre ignorante em outros aspectos é de grande valia para a reflexão ora proposta.

O que se defende, no mesmo sentido do que reflete Simone Diniz, é que a formação dos profissionais de saúde deve ser elaborada com a inclusão de pesquisas sobre violência obstétrica e direitos sexuais, reprodutivos e humanos nos currículos de ensino. Somente a partir da valorização desses temas é que será possível superar os estereótipos de gênero e combater a banalização da violência obstétrica ${ }^{34}$. Portanto, a educação constitui essencial instrumento na transformação do discurso hegemônico sobre a violência obstétrica em um discurso mais humano e feminista.

\footnotetext{
${ }^{32}$ DINIZ, Simone Grilo et al. op. cit., p. 3.

${ }^{33}$ MORIN, Edgar. Ciência com consciência. Tradução de Maria D. Alexandre e Maria Alice Sampaio Dória. Rio de Janeiro: Bertrand Brasil, 2000. p. 101.

${ }^{34}$ DINIZ, Simone Grilo et al. op. cit., p. 5.
} 
Em um segundo aspecto, a exigência de que sejam observados os princípios bioéticos do consentimento e da autonomia e os preceitos da dignidade, do acesso adequado da informação, entre outros já citados, nos procedimentos de assistência à saúde da mulher parturiente - contemplando pré-parto, parto, pós-parto e abortamento - constitui uma das formas de fortalecer o discurso minoritário, sendo uma articulação discursiva importante para o entendimento de que o tema da violência obstétrica é, de fato, afeto à bioética e, portanto, suas nuances são de observação obrigatória por parte dos profissionais da saúde. A observância dos princípios, portanto, constitui verdadeiro mecanismo para incentivar o exercício de outra articulação discursiva por parte dos agentes envoltos nos serviços de saúde, a fim de provocar uma mudança identitária nos grupos cujo discurso é atualmente hegemônico.

O terceiro elemento basilar para a transformação do discurso hegemônico nas maternidades e nos hospitais brasileiros é a permissão de inserção de outros agentes no cenário da maternidade, a exemplo das doulas. Trata-se de uma forma de integrar ao ambiente hospitalar concepções plurais de assistência obstétrica. Apenas como exemplo, cabe citar que o município de Rio Grande (RS) aprovou recentemente a Lei Municipal n. 8.286/2018 ${ }^{35}$, que obriga hospitais e estabelecimentos de saúde a permitir a presença das doulas em todos os procedimentos de acompanhamento do pré-parto, parto e pós-parto.

Por fim, o último elemento que se compreende fundamental para a transformação do paradigma discursivo nos serviços de saúde é justamente o necessário fortalecimento da constituição identitária das mulheres em torno da violência obstétrica. É preciso compreender que o debate acerca deste tema não atinge apenas determinados grupos de mulheres, mas sim a totalidade das mulheres - tanto aquelas que utilizam o sistema privado quanto as que utilizam o sistema público; tanto as mulheres que já tiveram seus corpos violentados por determinada prática cometida na assistência ao parto quanto as que já passaram pela experiência do parto humanizado, sem qualquer tipo de violência. Somente desta forma, a articulação discursiva posta ultrapassará a lógica da diferença e alcançará o estágio da lógica da equivalência social, momento em que deterá identidade fortalecida.

Nesse sentido, compreende-se que o fortalecimento dos quatro elementos elencados - investimento em formação profissional, prática diária dos princípios

\footnotetext{
${ }^{35}$ PREFEITURAMUNICIPALDERIO GRANDE. Lein.8,286, de21 denovembro de 2018. Dispõesobrea permissão da presença de doula durante todo o período do trabalho de parto, parto e pós parto imediato, bem como nas consultas de exames pré-natal, sempre que solicitado pela parturiente, na maternidade, hospitais e demais estabelecimentos de saúde no âmbito do município. Disponível em: https://leismunicipais. com.br/a/rs/r/rio-grande/lei-ordinaria/2018/829/8286/lei-ordinaria-n-8286-2018-dispoe-sobrea-permissao-da-presenca-de-doula-durante-todo-o-periodo-do-trabalho-de-parto-parto-e-pos-partoimediato-bem-como-nas-consultas-de-exames-pre-natal-sempre-que-solicitado-pela-parturiente-namaternidade-hospitais-e-demais-estabelecimentos-de-saude-no-mbito-do-municipio?q=8286. Acesso em: 12 maio 2021.
} 
bioéticos, inserção de outros agentes no âmbito dos serviços de saúde e fortalecimento da identidade discursiva em torno do tema - é essencialmente o principal mecanismo de abertura do discurso em prol de articulação discursiva que confira visibilidade ao tema da violência obstétrica, de maneira a contrabalancear a disputa do discurso hegemônico na área da saúde.

\section{Conclusão}

Os direitos e a própria dignidade das mulheres são sistematicamente desrespeitados ao longo da história da sociedade, especialmente no que tange aos direitos sexuais e reprodutivos. Inserido nesta categoria de direitos está o tema da violência obstétrica, entendida como toda e qualquer violação sofrida pela mulher no âmbito da assistência à gravidez. Assim, a violência obstétrica caracteriza-se como violações ocorridas no pré-parto, no parto, no pós-parto e no atendimento ao abortamento.

O tema por si só apresenta diversas problemáticas, sobretudo diante da forma estereotipada com que é encarado na sociedade. Os processos de naturalização e banalização dessa violência constituem um dos problemas centrais e acarretam invariavelmente o questionamento sobre o silenciamento da voz da mulher em maternidades em detrimento do discurso biomédico. Resta evidente que a reprodução sistêmica de determinados discursos consolidou uma hegemonia do discurso dos profissionais de saúde sobre o tema.

A partir desta realidade, o presente estudo objetivou verificar se a hegemonia do discurso dos profissionais da saúde é capaz de interferir na percepção dos casos de violência obstétrica. A análise do fenômeno social posto foi realizada por meio da teoria do discurso de Ernesto Laclau e de Chantal Mouffe, a partir do método dedutivo e da pesquisa bibliográfica.

Em um primeiro momento, o artigo apresentou as bases sobre as quais foi construído o debate acerca do tema, em uma perspectiva histórica, demonstrando que a Declaração Universal de Direitos Humanos de 1948 constituiu o marco inicial da discussão por parte dos movimentos feministas. Também foi apresentada a delimitação conceitual da violência obstétrica, bem como a análise a respeito de como se proteger desta violência no Brasil.

Estabelecida a análise conceitual do tema, o estudo apresentou a teoria do discurso defendida por Ernesto Laclau e por Chantal Mouffe na obra "Hegemonia e Estratégia Socialista", de 1985, em que os teóricos políticos defendem uma nova forma de analisar os processos sociais, políticos e hegemônicos em sociedade. Em suma, defendem que o poder hegemônico é produto de relações discursivas antagônicas entre diferentes grupos sociais. No campo das relações da saúde, as disputas discursivas são facilmente identificadas e revelam a hegemonia do discurso dos profissionais da saúde, influenciada por alguns fatores: a construção histórica da 
prevalência do conhecimento médico; o próprio ambiente em que são estabelecidas as articulações discursivas; o debate recente em torno do tema; e a diferença de poder entre os discursos propriamente.

A partir da aplicabilidade da teoria do discurso às relações estabelecidas no âmbito dos serviços de saúde, é possível identificar a influência do discurso hegemônico na própria percepção dos casos de violência obstétrica, visto que este discurso acaba por naturalizar os processos de violação com a inclusão destes nos protocolos médicos, por sua vez igualmente facilitadores de práticas de afronta à dignidade das mulheres por meio da violência de cunho psíquico e moral. Há, portanto, uma evidente afronta aos princípios bioéticos.

Assim, evidenciada a influência do paradigma atual para a perpetuação das situações de violência obstétrica, foram identificados os principais mecanismos para transformação deste discurso: investimento em formação profissional na área da saúde, prática diária dos princípios bioéticos, inserção de outros agentes no âmbito dos serviços de saúde e fortalecimento identitário dos grupos sociais que demandam a humanização das relações de saúde.

Portanto, resta evidente que a problemática em torno da produção de discursos na assistência de saúde à parturiente é fundamental para aprofundar o debate sobre a violência obstétrica e para que se possibilitem novas articulações discursivas em torno do tema, a fim de transformar o paradigma discursivo hegemônico.

\section{Referências}

DINIZ, Simone Grilo et al. Violência obstétrica como questão para a saúde pública no Brasil: origens, definições, tipologia, impactos sobre a saúde materna e propostas para a sua prevenção. Journal of Human Growth and Development, v. 15, n. 3, p 377-384, 2019. Disponível em: Disponível em: http://pepsic.bvsalud.org/pdf/rbcdh/v25n3/pt_19.pdf. http://dx.doi. org/10.7322/jhgd.106080.

ENGELHARDT JR., H. Tristam. Fundamentos da bioética. São Paulo: Loyola, 1998.

GRAMSCI, Antônio. Maquiavel, a política e o Estado Moderno. Rio de Janeiro: Civilização Brasileira, 1978.

LACLAU, Ernesto. Mouffe Chantal. Hegemonia e estratégia socialista: por uma política democrática radical. Tradução de Joanildo A. Burity, Josias de Paula Jr. e Aécio Amaral. São Paulo: Intermeios; Brasília-DF: CNPq, 2015.

LEAL, Maria do Carmo et al. A cor da dor: iniquidades raciais na atenção pré-natal e ao parto no Brasil. Cad. Saúde Pública, Rio de Janeiro, v. 33, supl. 1, 2017. Disponível em: https://www.scielo.br/pdf/csp/v33s1/1678-4464-csp-33-s1-e00078816.pdf. http://dx.doi. org/10.1590/0102-311X00078816. 
LEAL, Maria do Carmo; GAMA, Silvana Granado Nogueira da S. G. N. Nascer no Brasil: inquérito nacional sobre parto e nascimento. Sumário Executivo Temático da Pesquisa. Rio de Janeiro: Fundação Oswaldo Cruz, 2012. Disponível em: http://www.ensp.fiocruz.br/portalensp/informe/site/arquivos/anexos/nascerweb.pdf. Acesso em: 18 jun. 2019.

MARIANI, Adriana Cristina; NASCIMENTO NETO, José Osório do. Violência obstétrica como violência de gênero e violência institucionalizada: breves considerações a partir dos direitos humanos e do respeito às mulheres. Cad. Esc. Rel. Int. (UNIBRASIL), v. 2, n. 25, p 48-60, jul./dez. 2016. Disponível em: https://portaldeperiodicos.unibrasil.com.br/index. $\mathrm{php} /$ cadernosdireito/article/view/3060/2630.

MENDONÇA, Dianiel de; RODRIGUES, Léo Peixoto. (Orgs.). Pós-estruturalismo e teoria do discurso: em torno de Ernesto Laclau. Porto Alegre: EDIPUCRS, 2008.

MORIN, Edgar. A cabeça bem-feita: repensar a reforma, reformar o pensamento. Tradução de Eloá Jacobina. 10. ed. Rio de Janeiro: Bertrand Brasil, 2004.

MORIN, Edgar. Ciência com consciência. Tradução de Maria D. Alexandre e Maria Alice Sampaio Dória. Rio de Janeiro: Bertrand Brasil, 2000.

OBSTÉTRICA “Parirás com dor”. Dossiê elaborado pela Rede Parto do Princípio para a CPMI da Violência Contra as Mulheres. Brasília-DF: Senado Federal, 2012. Disponível em: https://www. senado.gov.br/comissoes/documentos/SSCEPI/DOC\%20VCM\%20367.pdf. Acesso em: 19 jun. 2019.

PALHARINI, Luciana Aparecida. Autonomia para quem? O discurso médico hegemônico sobre a violência obstétrica no Brasil. Dossiê Gênero e Ciências: histórias e políticas no contexto Ibero-americano. Cadernos pagu, n. 49, 2017, ISSN 1809-4449. Disponível em: https://www.scielo.br/pdf/cpa/n49/1809-4449-cpa-18094449201700490007.pdf. http://dx.doi. org/10.1590/18094449201700490007.

PEÑA, Rafaela de Miranda Ochoa. Vidas cortadas: a violência obstétrica sob uma perspectiva de gênero. 2016. Monografia (Graduação em Direito) - Faculdade de Direito, Universidade de Brasília, Brasília-DF, 2016. Disponível em: https://bdm.unb.br/bitstream/10483/14788/1/2016_ RafaelaDeMirandaOchoaPena_tcc.pdf.

PULHEZ, Mariana Marques. "Parem a violência obstétrica: a construção das noções de 'violência' e 'vítima' nas experiências de parto. RBSE- Revista Brasileira de Sociologia da Emoção, v. 12, n. 35, p. 544-564, ago. 2013. ISSN 1676-8965. Disponível em: https://grem-grei. org/wp-content/uploads/2020/05/n35_RBSEv12n35ago2013.pdf.

SENADO FEDERAL. Relatório Final da Comissão Parlamentar Mista de Inquérito da Violência Contra as Mulheres. Subsecretaria de Apoio às Comissões Especiais e Parlamentares de Inquérito, 2013. Disponível em: http://www.senado.gov.br/comissoes/documentos/SSCEPI/ DOC\%20VCM\%20367.pdf. Acesso em 20 jun. 2019.

VENTURI, Gustavo; BOKANY, Vilma. Pesquisa de Opinião Pública. Mulheres brasileiras e gênero nos espaços público e privado. Núcleo de Opinião Pública da Fundação Perseu Abramo, ago. 2010. Disponível em: https://apublica.org/wp-content/uploads/2013/03/www.fpa_.org_. br_sites_default_files_pesquisaintegra.pdf. Acesso em: 19 jun. 2019. 
Dias R. D., Lindenmeyer M. L., Simioni F., Tomaz W.

Renato Duro Dias - Doutorado em Educação pela Universidade Federal de Pelotas (UFPEL); mestrado em Memória Social e Patrimônio Cultural pela UFPEL; especialização em Direito de Família e Sucessões pela Universidade Luterana do Brasil (ULBRA); graduação em Direito pela UFPEL. Professor Adjunto na Faculdade de Direito e no Programa de Pós-Graduação em Direito da Universidade Federal do Rio Grande (FURG); pró-reitor de Graduação da FURG. Rio Grande/RS, Brasil.

Mariana Lannes Lindenmeyer - Mestranda no Programa de Pós-Graduação em Direito e Justiça Social da Universidade Federal de Rio Grande (FURG); especialização em Direito do Estado pela Universidade Federal do Rio Grande do Sul (UFRGS) e em Direito Processual Civil pela Escola Superior da Magistratura Federal do Rio Grande do Sul (ESMAFE); graduação em Direito pela FURG. Advogada. Rio Grande/RS, Brasil.E-mail: mariana_lannes@hotmail.com

Fabiane Simioni - Doutorado em Direito pela Universidade Federal do Rio Grande do Sul (UFRGS); mestrado em Direito pela Pontifícia Universidade Católica do Rio Grande do Sul (PUCRS); graduação em Ciências Jurídicas e Sociais pela Universidade do Vale do Rio dos Sinos (Unisinos). Professora Adjunta da Universidade Federal de Rio Grande (FURG). Rio Grande/RS, Brasil.

Wesley Tomaz - Mestrando em Direito e Justiça Social da Universidade Federal do Rio Grande (FURG); graduação em Direito pela FURG. Rio Grande/RS, Brasil. 